\title{
Diagnóstico sociolinguístico nas escolas municipais após a sanção à Lei $211 / 2014$, que cooficializou as línguas indígenas na sede do Município de Bonfim, Roraima
}

Sociolinguistic diagnosis in municipal schools after the sanction of the Law 211/2014, who co-officialized the indigenous languages at the headquarters of the Municipality of Bonfim, Roraima

\author{
Jama Peres Pereira ${ }^{1}$ \\ Ananda Machado ${ }^{1}$
}

DOI: http://dx.doi.org/10.20435/tellus.v19i40.628

\begin{abstract}
Resumo: Este artigo faz uma breve revisão bibliográfica de leis e estratégias de valorização cultural e linguística desenvolvidas com populações indígenas e que tenham conseguido contribuir para o multilinguismo. A fundamentação teórica buscou definir: política linguística, cooficialização de línguas, falantes ativos, passivos, multi e plurilinguismo. Observa o processo de sanção e de implementação da Lei 211/2014, de cooficialização das línguas Macuxi e Wapichana no município de Bonfim, Roraima, que aconteceu a partir da organização dos professores indígenas Macuxi e Wapichana da Região Serra da Lua (municípios de Bonfim e Cantá, Roraima). Divulga os resultados do diagnóstico sociolinguístico que foi realizado a partir de 2016 nas duas escolas municipais da sede do município de Bonfim, no Estado de Roraima, com o objetivo de identificar as línguas faladas, a quantidade de falantes, averiguar a forma como os alunos indígenas das escolas municipais na sede de Bonfim estão construindo suas identidades e reconhecendo ou não o valor de suas línguas. A relevância do estudo se justifica no fato de a cooficialização dessas línguas indígenas prever a realização desse diagnóstico sociolinguístico no município de Bonfim. A metodologia incluiu pesquisa de campo com aplicação de questionários aos discentes, professores e gestores das escolas municipais e a realização de entrevistas com alguns familiares dos alunos indígenas. Entre os resultados alcançados está a confirmação da diversidade linguística presente na sede do Bonfim e da necessidade de se criarem mecanismos que valorizem as línguas indígenas no contexto escolar, na sede e no município como um todo.
\end{abstract}

${ }^{1}$ Universidade Federal de Roraima (UFRR), Boa Vista, Roraima, Brasil. 
Palavras-chave: políticas linguísticas; línguas indígenas; Macuxi; Wapichana.

\begin{abstract}
This article makes a brief bibliographical review of laws and strategies of cultural and linguistic valorization developed with indigenous populations that have been able to contribute to multilingualism. The theoretical foundation sought to define: language policy, co-officialisation of languages, active speakers, passive, multi and plurilingualism. Observes the process of sanctioning and implementing Law 211/2014, co-officializing the Makushi and Wapishana languages in the municipality of Bonfim, Roraima, which took place through the organization of indigenous teachers Makushi and Wapishana in the Serra da Lua region (municipalities of Bonfim and Cantá, Roraima). Disseminates the results of the sociolinguistic diagnosis that was carried out from 2016 on in the two municipal schools of Bonfim, in Roraima State, in order to identify the spoken languages, the number of speakers, and find out how the indigenous students of the municipal schools at Bonfim headquarters are building their identities and recognizing or not recognizing the value of their languages. The relevance of the study is justified by the fact that the cooficialization of these indigenous languages predicts the realization of this sociolinguistic diagnosis in the municipality of Bonfim. The methodology included field research with questionnaires applied to students, teachers and managers of municipal schools and interviews with some family members of indigenous students. Among the results achieved is the confirmation of the linguistic diversity present at Bonfim headquarters and the need to create mechanisms that value indigenous languages in the school context, at headquarters and in the municipality as a whole.
\end{abstract}

Keywords: language policy; indigenous languages; Makushi; Wapishana.

\title{
1 INTRODUÇÃO
}

Esse artigo faz uma breve revisão bibliográfica de leis e estratégias de valorização cultural e linguística desenvolvidas com populações indígenas e que tenham conseguido contribuir para a construção do multilinguismo, tal como a política de cooficialização de línguas em nível municipal, que é referência importante no Brasil. A fundamentação teórica buscou definir: política linguística, cooficialização de língua, o conceito de falantes ativos, passivos, de multi e plurilinguismo.

A segunda parte da pesquisa reconstitui brevemente o processo de sanção e de implementação da Lei 211/2014 de cooficialização das línguas Macuxi e Wapichana no município de Bonfim, Roraima, que aconteceu a partir da organização dos professores indígenas Macuxi e Wapichana da Região Serra da Lua (municípios de Bonfim e Cantá, Roraima). A relevância do estudo se justifica no 
fato de a cooficialização dessas línguas indígenas prever a realização de um diagnóstico sociolinguístico no município de Bonfim.

Por último, o artigo divulga os resultados do diagnóstico sociolinguístico que foi realizado a partir de 2016 nas duas escolas municipais da sede do município de Bonfim, no Estado de Roraima, com o objetivo de identificar as línguas faladas, a quantidade de falantes, averiguar a forma como esses alunos indígenas estão construindo suas identidades e reconhecendo ou não o valor de suas línguas.

A metodologia incluiu pesquisa de campo com aplicação de questionários aos discentes, professores e gestores das escolas municipais e a realização de entrevistas com alguns familiares dos alunos indígenas.

Entre os resultados alcançados está a confirmação da diversidade linguística presente no município e da necessidade de se criarem mecanismos que valorizem as culturas e as línguas indígenas no contexto escolar, na sede e no município como um todo.

\section{REVISÃO BIBLIOGRÁFICA}

Como pondera James Tollefson (1991, p. 188), "os direitos linguísticos são baseados em luta" e "alcançar algum quinhão dos direitos não finda a luta; simplesmente muda a sua natureza", o que se aponta para a necessidade de uma mobilização permanente das lideranças indígenas em defesa dos direitos culturais e linguísticos.

Em nível mundial, a partir de 1992, algumas iniciativas trabalharam na defesa do plurilinguismo: Carta Europeia das Línguas Regionais ou Minoritárias - Conselho da Europa (1992); Declaração Universal dos Direitos Linguísticos - Organização das Nações Unidas para a Educação, a Ciência e a Cultura (UNESCO) (Barcelona, 1996); Declaração Universal sobre a Diversidade Cultural - UNESCO (2002); e Carta Europeia do Plurilinguismo - Jornadas Europeias de Plurilinguismo (2005-2009).

O multilinguismo e plurilinguismo são conceitos relacionados, mas não são sinônimos. Altenhofen e Boch (2011 apud IPHAN, 2016a, p. 34) diferenciam esses termos, classificam o multilinguismo como a "coexistência de línguas em determinado território", e o plurilinguismo como "a postura plural do indivíduo, refletida nas habilidades/competências em mais de uma língua". Neste sentido, 
enquanto o multilinguismo seria uma característica da sociedade, o plurilinguismo seria uma marca do indivíduo.

Há uma série de políticas construídas que atuam na defesa do multilinguismo. Para Calvet (1999), as línguas devem servir à humanidade, "porque afinal os homens não existem para servir às línguas, mas as línguas para servir aos homens". Para aprofundar a discussão, aproveitamos a ideia desse autor quando define política linguística:

[...] se trata das grandes decisões referentes às relações entre as línguas e a sociedade; em que língua o Estado funcionará e se relacionará com os cidadãos, em que línguas a educação e os serviços culturais serão oferecidos, que variedade de língua será usada, se as outras línguas faladas pelos cidadãos serão reprimidas, reconhecidas ou promovidas. (CALVET, 2007, p.1).

Oliveira (2016, p. 5) destaca: "construir políticas linguísticas é participar da construção do futuro das sociedades, e, mais especificamente, da nossa sociedade". E o autor continua: "Fazer política linguística, pela própria noção de intervenção sobre as línguas, sem a qual ela não existe, é atuar para um mundo mais justo neste campo específico das línguas e dos seus usos, mais plural, mais democrático e mais aberto à ecologia de saberes humanos". Essas ideias nos ajudam a justificar o valor do trabalho que vimos se desenvolvendo em Roraima.

Hamel (1988), referindo-se à inter-relação entre política linguística e identidade, ressalta que as políticas linguísticas produzem transformações na identidade cultural dos grupos sociais, uma vez que geram transformações na base interpretativa desses grupos pelas mudanças nos padrões culturais de interação e de interpretação do mundo. Um exemplo dessas transformações ocorre quando cidadãos se veem impedidos de usar sua língua materna e obrigados a utilizar outra língua em diversas situações sociais, como acontece com os falantes de línguas indígenas.

O Brasil, historicamente, é um país multilíngue. Antes da chegada dos colonizadores portugueses, a diversidade de línguas indígenas aqui faladas era imensa. Aryon Rodrigues (1993) estima que fossem cerca de 1.200 línguas. Durante a colonização, vieram para o país, além do português, línguas africanas e línguas de outros imigrantes, que se tornariam mais diversas ainda nos séculos posteriores. 
O censo do IBGE 2010 apontou 274 línguas indígenas faladas por 305 etnias diferentes; as línguas indígenas estão distribuídas em dois grandes troncos: Tupi e Macro-Jê; e em quarenta famílias, além de treze ou mais línguas isoladas (sem parentesco genético com outras línguas). Elas estão dispersas em boa parte do território nacional, mas especialmente na Amazônia, que concentra a maior diversidade linguística do país (IPHAN, 2016a). Essa multiplicidade de línguas convivendo no território nacional envolve questões linguísticas complexas de comunicação, de acesso à informação, de ensino e de cidadania. A Língua Macuxi é Karib, e a Wapichana, Aruak.

Embora seja um país multilíngue, Carlos Alberto Faraco (2002, p. 13-4) observa que o Brasil, "em geral, se reconhece como unilíngue, confundindo hegemonia com unicidade". Assim, a grande questão das centenas de línguas indígenas, das dezenas de línguas de imigração e das de origem africana não se configura ainda como um tema importante da nacionalidade e da cidadania.

Apesar desse quadro multilingue, essa diversidade está ameaçada. Por isso uma parcela da sociedade, que inclui lideranças indígenas, educadores, pesquisadores, políticos e organizações não governamentais, tem se mobilizado cada vez mais para influenciar políticas linguísticas no país, embora os resultados dessas atuações ainda sejam pequenos diante da pressão que a imposição da Língua Portuguesa produz.

A discriminação por religião, etnia, entre outras, encontra amparo jurídico em legislações nacionais e internacionais, todavia, de acordo com essas legislações, o preconceito linguístico ainda não pode ser penalizado. Assim, os falantes de línguas indígenas e de línguas de imigração no Brasil são vulneráveis a várias práticas de exclusão e a esses preconceitos linguísticos, em virtude do não domínio ou domínio apenas parcial da Língua Portuguesa (MORELLO, 2015).

Homi Bhabha (2003) pensa a importância de momentos híbridos de mudança política, ressaltando os potenciais transformadores e as possibilidades de rearticulação. A partir das ideias do autor, Machado (2016, p. 54) afirma:

[...] no movimento de deslocamento de fronteiras, o plurilinguismo é saudável como postura em uma sociedade plural na relação com suas línguas e culturas, abrindo possibilidades para o uso dessas línguas e aumentando o papel das comunidades de fala, viabilizando uma "pedagogia para o plurilinguismo". 
O Brasil pode ser considerado um país multilíngue devido à quantidade de línguas faladas em seu território. Essa diversidade linguística, no entanto, está ameaçada por causa do número reduzido de falantes por língua. Maher (2010, p. 117) afirma que, "além do português, são faladas, hoje, em nosso país, mais de 222 línguas [...]. Dessas línguas, pelo menos 180 são línguas indígenas [...]”. E essas 180 línguas encontram-se em situação de risco de desaparecimento devido ao número reduzido de falantes e à falta de políticas linguísticas que ajudem a preservar, a valorizar e a divulgar entre os seus membros a própria língua, dando um sentido de pertencimento e identidade ao grupo. O número reduzido de falantes de algumas línguas minoritárias mostra a vulnerabilidade linguística que muitos povos indígenas estão enfrentando.

Como Calvet (2007) e Maher (2010) afirmam: as causas para esse comprometimento devem-se principalmente à falta de documentação e de implementação de políticas por parte do Estado com as comunidades, que efetivamente ajudem a manter essas línguas. Nessa direção, o uso das línguas indígenas merece atenção e precisa ser prestigiado.

As línguas indígenas guardam nomes e conhecimentos que apenas quem fala e entende pode ter acesso, além disso, somos responsáveis por proteger e entender os processos sociais e de memória e esquecimento desses bens culturais que, além dos povos indígenas, são patrimônio da humanidade. (MACHADO, 2016).

Portanto, há muito do que, para ser lembrado, precisa do conhecimento da língua do povo. Assim, as políticas linguísticas podem contribuir para uma maior conexão entre as línguas e todo o universo humano, seus interesses, suas necessidades e suas visões de futuro. Franchetto (2005, p. 188) afirma que "a preservação das línguas é a parte dos direitos humanos e instrumento de autonomia política".

Para Veiga (2001, p. 137), “o Estado brasileiro não tem realmente uma política linguística específica para as sociedades indígenas. Tem sim, no nível do discurso, uma política de educação escolar indígena, qualificada como "bilíngue, intercultural, específica e diferenciada". Por mais que tenhamos experiências enriquecedoras, o bilinguismo, a interculturalidade, as especificidades e o diferente ainda precisam ser efetivados na maior parte das escolas indígenas. 
Ou seja, as políticas linguísticas voltadas para os povos indígenas estão publicadas, algumas leis sancionadas, mas, na prática, acontece pouca valorização das línguas e fortalecimento dos fazeres culturais dos povos indígenas. E o ideal seria que eles fossem os atores, organizando propostas e elaborando mudanças que partam de seus reais anseios.

Em nível federal, como política linguística, o Brasil oficializou a Língua Brasileira de Sinais (Libras), ao lado da Língua Portuguesa, através da Lei 10.436, de 24 de abril de 2002. Posteriormente, o Decreto n. 7.387, de 9 de outubro de 2010, instituiu o Inventário Nacional da Diversidade Linguística (INDL), mecanismo pelo qual até o momento as línguas Talian, Asurini do Trocará, Guarani Mbya, Nahukuá, Matipu, Kuikuro e Kalapalo receberam o certificado de Referência Cultural Brasileira pelo Instituto do Patrimônio Histórico e Artístico Nacional (IPHAN).

O IPHAN desenvolve linhas de atuação (reconhecimento, apoio e fomento) e disponibiliza dois volumes do Guia de Pesquisa e Documentação para o INDL, divulgando suas metodologias de inventário. O INDL vem sendo um instrumento oficial importante no reconhecimento de línguas como patrimônio cultural.

A política de cooficialização de línguas em nível municipal é outra referência de política linguística importante que é recente no Brasil. "Oficializar uma língua significa que o estado reconhece sua existência e reconhece aos seus falantes a possiblidade de não terem que mudar a língua sempre que queiram se expressar publicamente ou tratar de aspecto de sua vida civil" (OLIVEIRA in MORELLO, 2015, p. 27).

A cooficialização das línguas indígenas, de acordo com o texto constitucional brasileiro, não promove ilegalidade, uma vez que não contradiz nem se contrapõe à Constituição Federal; ao contrário, expande para outros espaços públicos os direitos assegurados constitucionalmente aos espaços educacionais das demais línguas. Ou seja, significa que ela se torna oficial ao lado de outra língua que já goza o estatuto de oficialidade, como é o caso da Língua Portuguesa no Brasil (OLIVEIRA in MORELLO, 2015).

Sabemos que a língua de muitos povos indígenas no Brasil, com o assassinato da própria língua, se tornou a portuguesa. Mas se as comunidades reconhecerem o valor das línguas indígenas, elas poderão retomá-las e assim 
fortificar seu uso. Se a história não aconteceu da forma que gostaríamos, cabe a nós então reconstrui-la daqui para frente, construindo ações do planejamento de aquisição e constituindo instrumentos legais relevantes para a valorização das línguas indígenas. (MACHADO, 2016).

A cooficialização, além de outros direitos linguísticos, garante que se possam utilizar línguas próprias para produzir o conhecimento de que se necessite para a vida, podendo-se, assim, deixar "contribuição epistemológica específica à história humana" (OLIVEIRA in MORELLO, 2015, p. 27).

Até hoje, 17 municípios, de sete estados brasileiros, trabalharam para cooficializar 12 línguas, oito indígenas e quatro de imigração: o Nheengatu, o Baniwa, o Tukano, o Pomerano, o Talian, o Hunsrückisch, o Guarani, o Alemão, o Xerente, o Macuxi, o Wapichana e o Ingarikó. No entanto há mais de cem municípios, em diversos estados brasileiros, com falantes de outras línguas que não o português, mas que ainda não as cooficializaram.

Há pelo menos 20 municípios no Brasil com a população majoritariamente indígena. Portanto políticas linguísticas de promoção das línguas brasileiras são extremamente necessárias. É preciso levar o Estado a reconhecer que a(s) língua(s) nele falada(s) é(são) língua(s) própria(s) daquele território (OLIVEIRA in MORELLO, 2015).

A Constituição da República Federativa do Brasil (1988) trouxe expectativa positiva e de esperança para os povos indígenas, pois assegurou artigos importantes, reconhecendo direito à organização social, às culturas e à própria educação. Nessa Constituição, no artigo 30, incisos I e IX, está definido que compete aos municípios o predomínio do interesse local, portanto ressalta-se como prerrogativa para a cooficialização de línguas o interesse de cada município em proteger o patrimônio histórico e cultural local. Essa série processos é relevante na luta histórica por direitos linguísticos no Brasil, pois "instala procedimentos jurídicos inovadores que encontram forte repercussão social e rápida aplicação em contextos de línguas diferentes" (MORELLO, 2015, p. 81).

As cooficializações vêm desencadeando ações de apoio, fomento e promoção das línguas brasileiras e dos grupos sociais que as falam. A Lei n. 145/2002, que dispõe sobre a cooficialização das línguas Nheengatu, Tukano e Baniwa no município de São Gabriel da Cachoeira, AM, foi a primeira na história do Brasil 
a estabelecer o status de línguas cooficiais a 3 línguas indígenas. A lei obrigou o município a prestar os serviços públicos básicos de atendimento nas repartições públicas na língua oficial e nas línguas cooficiais, a incentivar e apoiar o aprendizado e o uso dessas línguas nas escolas e nos meios de comunicação.

No entanto, a maior parte das ações previstas nessas leis de cooficialização de línguas ainda não foi implementada. A regulamentação da oficialização da Lei 145/2002 acrescentou detalhes, priorizou ações e nomeou órgãos responsáveis por elas. Obriga que todos os concursos em nível municipal deverão oferecer provas nas quatro línguas oficiais. Definiu, por exemplo, que as repartições públicas municipais que não dispusessem de funcionários deveriam contratar falantes com competência e habilidade oral e escrita nas línguas cooficiais, mostrando que o conhecimento da língua pode trazer vantagem econômica (MACHADO, 2016).

É na fase de implementação ainda que está prevista a formação de quadros de professores das línguas cooficializadas. E são muito importantes os atos que garantam a presença dessas línguas nos espaços públicos, como as placas de trânsito, os atos administrativos municipais, as campanhas de saúde e de transmissões midiáticas (OLIVEIRA, in MORELLO, 2015, p. 29).

\section{OS PROFESSORES DE LÍNGUAS INDÍGENAS DA REGIÃO SERRA DA LUA E A LEI DE COOFICIALIZAÇÃO DAS LÍNGUAS MACUXI E WAPICHANA}

Em Roraima, foram os professores de língua indígena da Região Serra da Lua (RSL) que iniciaram o processo que resultou na cooficialização das línguas Macuxi e Wapichana no município de Bonfim. A RSL está localizada na porção Centro-Leste do Estado de Roraima, nos municípios de Bonfim e Cantá, no Brasil. Localiza-se na área fronteiriça com a República Cooperativa da Guiana. A Serra da Lua é um imenso maciço rochoso formado por material granítico e quartzito, o qual faz parte do Complexo Guianense. A serra se destaca na paisagem por atingir $1.000 \mathrm{~m}$ de altura e por ser um divisor natural entre as pediplanícies do Rio Branco ao Norte e Floresta Amazônica ao Sul. Seu nome certamente vem da tradução do topônimo Wapichana, Kayz Dyky'u, em que kayz é lua e dyky'u é serra (CARNEIRO, 2007, p. 86). 
Figura 1 - Mapa das Terras Indígenas da Região Serra da Lua

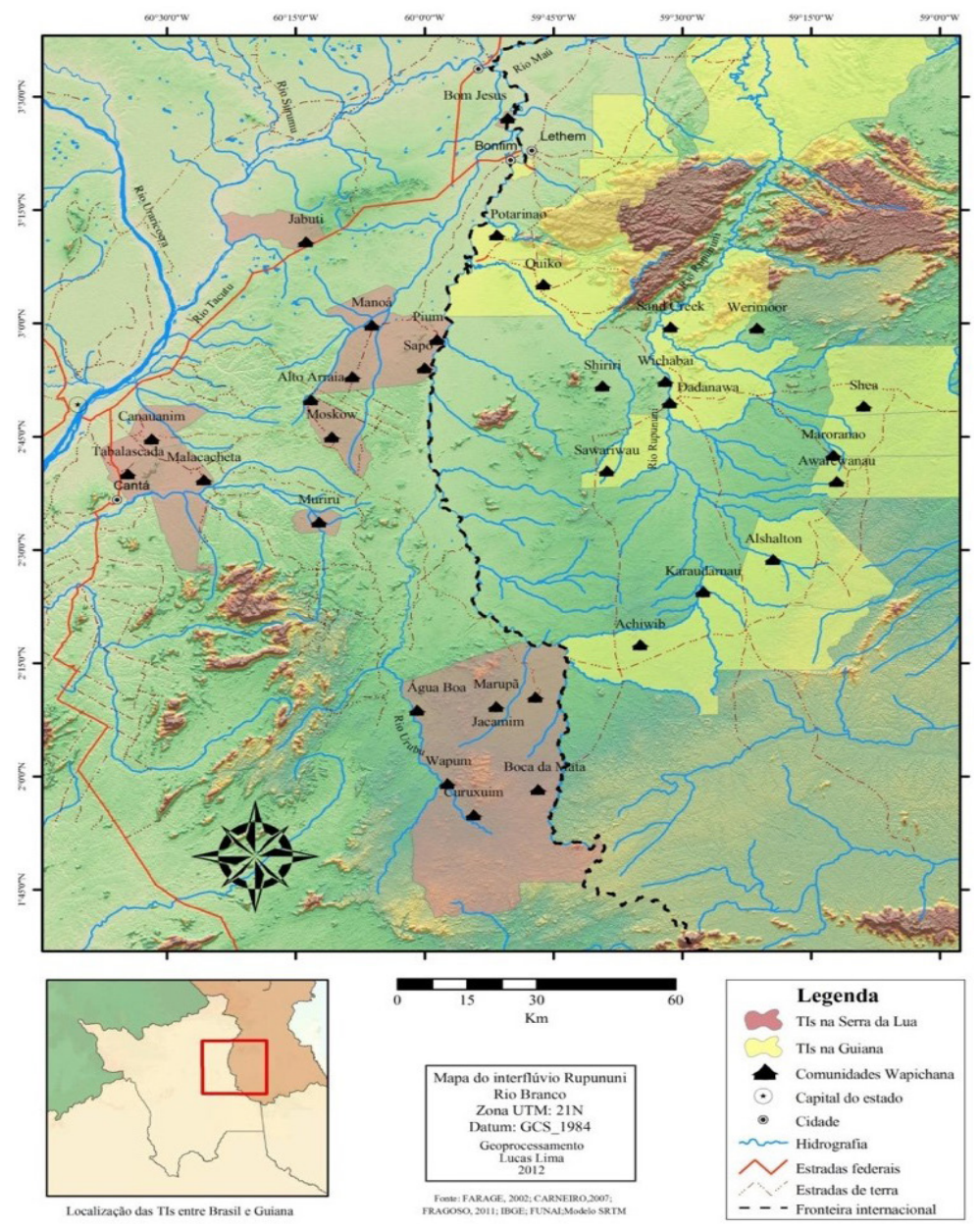

Fonte: Oliveira (2012).

O encontro dos professores de línguas da Região da Serra da Lua é fruto do trabalho de um grupo de professores que, desde novembro de 1992, passou a se reunir anualmente. Esse movimento tem sido fortificado desde 2012, pela parceria com o Programa de Valorização das Línguas e Culturas Macuxi e Wapichana (Extensão, UFRR). Essas ações estão cada vez mais reconhecidas pelos movimentos indígenas em Roraima como um todo.

A partir dessa parceria, algumas políticas linguísticas e ações importantes começaram a acontecer de modo mais sistemático. Em 2013, foi construída a 2a 
Edição do Dicionário Wapichana Paradakary Urudannaa. Em janeiro de 2015, com o apoio do Museu do Índio/Fundação Nacional do Índio (FUNAI), houve a publicação da 1 a Edição do livro didático Wapichan Paradan Idia'an, Aichapkary pabinak na'ik Kadyzyi Kid. Assim, foi dado um impulso maior na construção e publicação de materiais didáticos Wapichana. "Há uma necessidade de valorizar os conhecimentos indígenas manejados pelos mais idosos, registrados e transmitidos oralmente" (MACHADO, 2016).

Cooficializar tal como as lideranças da Região Serra da Lua fizeram com as línguas Wapichana e Macuxi no município de Bonfim (Lei 211/2014) e, posteriormente, de Cantá (Lei 281/2015) foi uma forma de dar encaminhamentos claros e precisos sobre a formação de professores indígenas, reconhecendo-Ihes as peculiaridades do âmbito específico de sua atuação.

A cooficialização no município de Bonfim inicialmente foi aprovada no encontro dos professores de Língua Macuxi e Wapichana da Região Serra da Lua, em abril de 2012. Depois, a proposta foi apresentada na Assembleia Regional dos Tuxauas da Serra da Lua, que teve lugar na comunidade Malacacheta em dezembro do mesmo ano. O vereador indígena Zacarias Douglas encaminhou a proposta em sessão com mais de trinta indígenas da Região Serra da Lua presentes na Câmara de Vereadores.

Lisete Spies (entrevista realizada em 2018), ex-prefeita que sancionou em 2014 a lei da cooficialização, afirmou:

É muito importante para os indígenas a cooficialização. É um direito social do cidadão. A prefeitura e a Secretaria Municipal de Educação têm que tomar para si a responsabilidade e assumir, promover. O município carece de tradutores no Cras, Creas, prefeitura, no setor de justiça, setores estes que atendem pessoas vulneráveis, que não falam português, há casos no Bonfim de pessoas que foram presas por não saber se defender em português porque a sua língua era Macuxi.

O artigo 4 da Lei 211/2014 promulga que "em nenhum caso alguém pode ser discriminado por razão da língua oficial ou em qualquer das cooficiais que use" (BONFIM, 2014). A lei prevê penalidades a esse tipo de discriminação.

Na área da educação, desde 1996, a legislação nacional trata dessa questão. Na Lei de Diretrizes e Bases da Educação Nacional n. 9.394/96 (LDB), os artigos 32 e 79 são uma conquista dos povos, possibilitando a preservação das línguas 
indígenas. Com base nos direitos adquiridos com esta lei, todos os municípios deveriam oferecer ensino de línguas indígenas em todas as escolas indígenas. "Não basta contratar, é preciso mais do que isso, que o Estado e os Municípios disponibilizem materiais, formação continuada para a aprendizagem de metodologias adequadas ao ensino das línguas indígenas como primeira ou segunda língua" (MACHADO, 2016, p. 61).

As línguas indígenas devem estar presentes nas escolas indígenas da Educação Infantil ao Ensino Médio, de preferência com uma prática bilíngue (LDB, artigos 78 e 79) - acrescentamos que isso deveria acontecer nos casos em que ainda seja possível, porque há comunidades com poucas famílias de falantes de língua indígena.

Percebemos que as comunidades com número razoável de falantes têm seus padrões estabelecidos para a socialização da língua, porém, para o ensino da língua indígena como segunda língua, ainda não há padrões, nem materiais didáticos (MACHADO, 2016). As comunidades buscam formação de linguistas indígenas bilíngues para trabalhar análise linguística e aprofundar os estudos das línguas.

A Região Serra da Lua foi inteiramente contemplada com a cooficialização de línguas em nível municipal, uma vez que suas comunidades estão nos municípios de Bonfim e Cantá. Uma das principais reivindicações que deram origem ao desejo de cooficializar as línguas foi a de que esses municípios abrissem concurso visando à contratação dos professores de línguas indígenas, para que eles pudessem atuar também nas escolas municipais, dado que em Roraima apenas as estaduais ofereciam ensino de línguas indígenas.

A publicação do edital com a minuta do concurso público 01/2015 foi uma das primeiras ações de implementação da Lei 211/2014 no município de Bonfim. Foram abertas duas vagas para professor de Língua Wapichana e duas para o ensino de Língua Macuxi, podendo os candidatos ser aprovados apenas com nível médio (MACHADO, 2016).

De acordo com entrevista realizada com a Secretária de Educação (2017), a Prefeitura de Bonfim tem contribuído na qualidade da educação indígena nas comunidades, "tal como foi realizado o primeiro concurso para professores das Línguas Macuxi e Wapichana". Essa informação foi confirmada pela concursada Benedita André, professora de Língua Wapichana: 
Em relação ao concurso realizado pelo município Bonfim, foram aprovados e chamados 2 Wapichana e 2 Macuxi, cada professor fica em uma comunidade, mas houve erro neste concurso, houve uma troca, onde se pedia uma tal língua, foi colocada outra, incompatível com o povo da comunidade, ou seja, não foi consultada a comunidade.

Para a professora entrevistada, o município ainda tem a aprender com essa experiência, mas já houve uma grande diferença porque, como efetiva: "nos sentimos mais seguros" e não precisa a cada seletivo (processo de contratação temporário) ficar desempregada, correr o risco de não conseguir escola ou precisar mudar de comunidade (entrevista realizada com Benedita André no XV Encontro dos Professores de Línguas Indígenas, Região Serra da Lua, na comunidade Cumaru, Bonfim, no dia 16/10/2017).

\section{UM LEVANTAMENTO SOCIOLINGUÍSTICO NAS ESCOLAS MUNICIPAIS DE BONFIM}

Localizado ao Leste do Estado de Roraima, na margem esquerda do Rio Tacutu e na Fronteira Brasil-República Cooperativa da Guiana, a sede do município de Bonfim é ligada a Boa Vista pela BR-401, com a distância de 125 quilômetros. O município tem 11.632 habitantes e 40\% de sua população é indígena das etnias Macuxi e Wapichana (IBGE, 2010).

No século XIX, formou-se na localidade um povoado que recebeu o nome de Bonfim. Uma das versões sobre a origem do nome do município explica que tem relação com um antigo sítio religioso de uma missão norte-americana.

Estar em área de fronteira é um fator que favorece a diversidade linguística, pois permite o contato entre falantes das línguas Macuxi, Wapichana, Inglês e Português, sendo de maior prestígio o Português e o Inglês. O Inglês é a língua estrangeira mais falada pelos guianenses e por muitos brasileiros residentes em Bonfim.

A Língua Portuguesa era o único idioma oficial do Bonfim e, pela Lei 211/2014, tornaram-se cooficiais as línguas Macuxi e Wapichana, sendo elas as línguas indígenas mais presentes no cenário bonfinense. No entanto poucos são os indivíduos residentes na sede municipal que, quando consultados, assumem ser falantes dessas línguas indígenas. Nas escolas, muitos alunos, bem como profes- 
sores, possuem semelhanças físicas com indígenas, porém negam sua identidade e seu conhecimento das línguas e culturas dos povos indígenas.

Pereira abordou a diversidade linguística/cultural existente na fronteira Brasil-Guiana:

Os conflitos externalizados nas relações interétnicas e intra-étnicas naquela fronteira impõem-se à observação etnográfica em sutis situações do dia-a-dia, em microrrelações do cotidiano que expressam o estranhamento da ordem cultural do "outro" [...] A integração social desses povos que vivem na fronteira não está posta em xeque por causa desses conflitos, ou do efeito da friç̧ão interétnica, que, no interior de cada Estado-nação, e entre eles, pode surgir. Longe de inviabilizarem a integração social entre grupos étnicos diferentes ajudam a construir e revitalizar suas identidades étnicas e nacionais. (PEREIRA, 2007, p. 357).

Alessandra Santos (2012) pensa o mesmo que Pereira, ao explicar que a diversidade de línguas e culturas não acarretou nenhum empecilho para a integração dos diferentes grupos à região do Bonfim. Os espaços de convivência de falantes de diferentes línguas, como é o caso das escolas de Bonfim, envolvem todos os pontos das relações entre língua, cultura e identidade. A linguista afirma: "É observada a sobreposição de uma língua sobre a outra, ou até mesmo a anulação de uma das línguas envolvidas [...]" (SANTOS, 2012, p. 34).

O Bairro São Francisco, conhecido também como a Beira, por ser próximo ao Rio Tacutu, onde se localiza a Escola Municipal Oscar Fernandes Costa (EMOFC), tem a população de aproximadamente 600 pessoas, com 127 famílias e 380 estudantes. Desses, 40\% são Wapichana e 30\% Macuxi. Os outros 28\% são de outros povos ${ }^{2}$. A unidade escolar EMOFC é formada, em sua maioria, por alunos residentes nas proximidades da escola e por alunos residentes na República Cooperativa da Guiana.

A EMOFC é conhecida no município por ser uma escola que atende a muitos alunos indígenas. Há outra escola municipal na sede, a Maciel Ribeiro Vicente da Silva (EMMRVS), localizada no Bairro Cidade Nova, que atende aos alunos de diferentes classes sociais.

2 Informações constantes em documento com dados coletados pelo morador e Presidente da Associação do Bairro São Francisco, Paulo Costa Afonso (2015). 
O levantamento sociolinguístico foi realizado no ano de 2016, com os alunos falantes de línguas indígenas de 6a ao 9a ano dessas duas escolas da rede municipal de Bonfim. Observamos como os alunos estão construindo suas identidades enquanto indígenas e reconhecendo ou não o valor de suas línguas. Tratamos mais especificamente das línguas Macuxi e Wapichana no contexto da diversidade linguística em Bonfim.

O levantamento de informações populacionais do município de Bonfim foi trabalhado especificamente no Bairro São Francisco. Para isso, fez-se a leitura de documentos históricos da Associação de Moradores e daqueles disponíveis no site do Instituto Brasileiro de Geografia e Estatística (IBGE), bem como de informações obtidas em entrevistas e conversas com os moradores de Bonfim.

Aplicamos questionários aos alunos, professores e gestores da Escola Municipal Oscar Fernandes Costa, com a finalidade de construir um diagnóstico que permitisse visualizar o panorama linguístico do referido espaço escolar, descrevendo as línguas faladas pelos discentes e aprofundando especificamente informações sobre os falantes das línguas Macuxi e Wapichana. O questionário continha as perguntas: pertencente a qual etnia? Sente vergonha de falar a língua indígena? Qual é a importância de manter o uso da língua indígena? Quais as línguas que usa no seu convívio diário? Passou por algum processo migratório?

Os agentes da Secretaria Municipal da Educação de Bonfim também responderam ao questionário, com o objetivo de obtermos as informações iniciais sobre a rede escolar municipal e as devidas autorizações para as visitas às unidades escolares. Esse questionário destinado aos docentes, gestores, coordenadores pedagógicos e à Secretaria Municipal de Educação buscou informações como: quais línguas falam? Identificam a presença das línguas indígenas dentro do espaço escolar que trabalham? O que poderia ser feito para que todos valorizem as línguas e culturas indígenas dentro do espaço escolar?

Realizamos também entrevistas com alguns familiares dos discentes da EMOFC declarados falantes e os que identificamos que suas famílias também são falantes, moradores do Bairro São Francisco, com a finalidade de observar como estão construindo suas identidades indígenas e reconhecendo o valor de suas línguas no espaço familiar. Para eles, acrescentamos perguntas a mais do que as do questionário, sobre qual a importância de manter a língua e a cultura indígena; 
o que a língua representa para eles como povos indígenas; quais soluções sugerem para fortalecer o uso das línguas e culturas Macuxi e Wapichana; se sabiam da existência da Lei Municipal 211/2014. Nessa etapa da pesquisa, identificamos muitas situações de contato entre línguas.

Com a mesma finalidade e metodologia, posteriormente, também realizamos a aplicação de questionários aos discentes, professores e gestores da Escola Municipal Maciel Ribeiro Vicente da Silva. No entanto não aplicamos os questionários e nem entrevistamos os familiares dos alunos dessa segunda escola.

Depois, trabalhamos a sistematização e análise das informações coletadas, com a finalidade de organizar os dados e, dessa forma, obter o resultado do diagnóstico sociolinguístico. A análise de cada etapa da pesquisa e o cruzamento dos resultados encontrados permitiram construir um panorama linguístico das escolas municipais Oscar Fernandes Costa e Maciel Ribeiro Vicente da Silva.

Apresentamos, a seguir, uma descrição de cada escola e dos resultados. Alguns dados foram transformados em gráficos para termos uma visão mais clara do panorama linguístico, especificando a quantidade de falantes das línguas Macuxi e Wapichana nas escolas da sede do município de Bonfim.

As duas escolas municipais oferecem Educação Infantil e os dois segmentos do Ensino Fundamental. Segundo a vice-gestora da Escola Municipal Oscar Fernandes Costa, Altacir Vitorina, a EMOFC tem um grande quantitativo de crianças indígenas da sede do município. Como resultado dos questionários dos alunos dessa escola, temos: a Língua Portuguesa não é a primeira língua de todos os discentes: há casos nos quais a primeira língua é o Inglês. Alguns alunos declararam não ser falantes de determinadas línguas, mas percebemos que eles compreendem palavras dessas línguas. As línguas citadas nestes casos foram: Macuxi e Wapichana, tendo tanto falantes parciais (passivos) como fluentes (ativos).

São denominados falantes fluentes: "pessoas que, no mínimo, podem se comunicar de forma natural e espontânea numa língua, em diferentes situações comunicativas do dia-a-dia" (IPHAN, 2016a). E falantes parciais são: "pessoas que têm uma compreensão razoável da língua, mas que não produzem conversações e outros usos linguísticos do mesmo modo como falantes fluentes". Em geral, "entendem bem, mas falam pouco sua língua", ou "entendem um pouco, mas 
não falam a língua". Isso decorre devido a uma aquisição parcial, sobretudo na infância e adolescência (IPHAN, 2016a).

No ambiente familiar, os discentes convivem com as seguintes línguas: Português, Inglês, Macuxi e Wapichana. Entre as línguas indígenas citadas, a Língua Wapichana foi a mais mencionada por professores e gestores da EMOFC.

O gráfico abaixo foi elaborado a partir do questionário aplicado no dia 26 de julho de 2016 para o Levantamento Sociolinguístico na Escola Municipal Oscar Fernandes Costa, realizado com 45 estudantes do Ensino Fundamental do 6 ao 9 ano, que se se autodeclararam indígenas. Todos são falantes da Língua Portuguesa e as outras línguas faladas por estes estudantes são: Inglês (41,3\%), Wapichana (29,49\%), Macuxi (28,21\%) e Espanhol. Portanto encontramos bastante diversidade linguística entre eles. $26,67 \%$ dos discentes que fizeram parte da pesquisa falam dois idiomas e 73,33\% deles falam três idiomas. Entre os 22 falantes da língua Macuxi, 8 são falantes fluentes e 14 são falantes parciais. Dos 23 estudantes que participaram da pesquisa e são da etnia Wapichana, 14 são falantes fluentes (ativos) e nove falantes parciais (passivos).

Gráfico 1- Falantes ativos e parciais (Língua Macuxi)

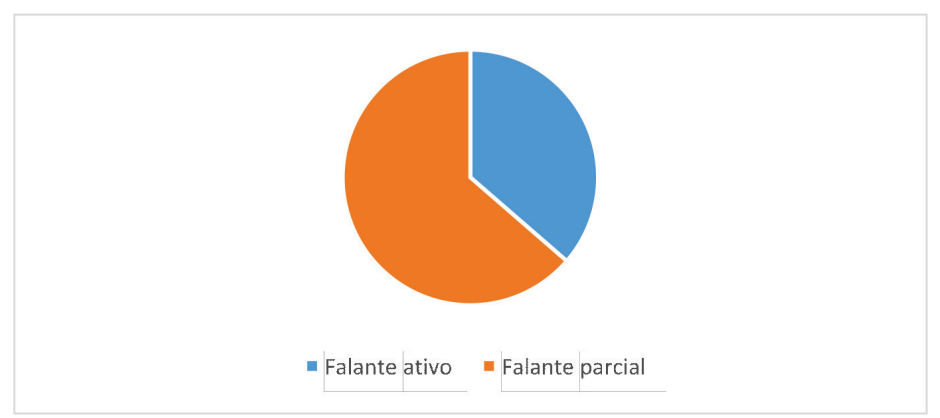

Fonte: As próprias autoras (2018).

No questionário destinado aos docentes, gestores e coordenadores pedagógicos, segundo os cinco professores entrevistados, é raro observar no ambiente escolar situações de diálogo nas línguas indígenas, os falantes se sentem intimidados e com vergonha de se expressar. Em 2017, os professores promoveram um Festival Cultural, com objetivo de valorizar as culturas locais. Segundo o atual gestor, Jones: 
Muitas dessas crianças que vêm das comunidades da Serra da Lua (Bonfim): como Manoá, Pium são falantes de três idiomas: Wapichana, Inglês e português. Há preconceito com eles mesmos, têm vergonha de falar, não há incentivo pela escola e também, muitas vezes, nem de casa. Deve, sim, valorizar, sim, as línguas e as culturas indígenas.

Na Escola Municipal Maciel Ribeiro Vicente da Silva também aplicamos os questionários às turmas do 6으 ao 9 ㅇ ano. A diferença foi na aplicação, em que foi trabalhada a leitura dos questionários em conjunto com todos os alunos de cada turma. Houve um total 23 discentes que se declararam falantes de línguas indígenas. De acordo com os questionários aplicados a estes: todos são falantes de Português e as outras línguas citadas por esses alunos foram o Inglês, Espanhol, Macuxi e Wapichana. Eles convivem com algumas dessas línguas no ambiente familiar. De acordo com os resultados da pesquisa, há 17 falantes de Macuxi e 6 de Wapichana. Para abordar mais especificamente, entre os alunos falantes de Língua Wapichana, quatro são falantes ativos e dois são passivos e, entre os Macuxi, 16 são passivos e um é ativo.

O gestor Emerson Martins disse que ouviu falar sobre a cooficialização das línguas Macuxi e Wapichana através dos jornais. Ao ser questionado sobre o fato de as línguas deverem ser ensinadas nas escolas da sede, ele considerou que é mais viável aplicar o ensino, como já acontece, nas comunidades indígenas. Acha complicado o ensino das línguas indígenas na sede por conta da diversidade presente. Disse que "deve, sim, valorizar as línguas e culturas, pois vêm perdendo suas raízes culturais. Vendo de fora, alguns são tímidos, não valorizam sua própria cultura" (Entrevista realizada em Bonfim, dia 22 de março de 2018).

De acordo com Marliete dos Santos, coordenadora pedagógica da unidade, é complicado o ensino da língua indígena na sala de aula na sede. "É peculiar trabalhar 3 idiomas". Ela acha que devem falar a língua em casa. "Precisa trabalhar a formação desses professores de línguas indígenas para saberem como atuar em suas salas de aula ou haver uma formação mais específica " (Entrevista realizada na sede de Bonfim, em 22 de março de 2018).

Entre os alunos que responderam os questionários na Escola Municipal Maciel Ribeiro Vicente da Silva, 5 falam a língua Wapichana, 18 falam Macuxi, 13 falam inglês e nenhum fala espanhol. 
Gráfico 2- Falantes ativos e passivos das línguas Wapichana e Macuxi na EMMRVS

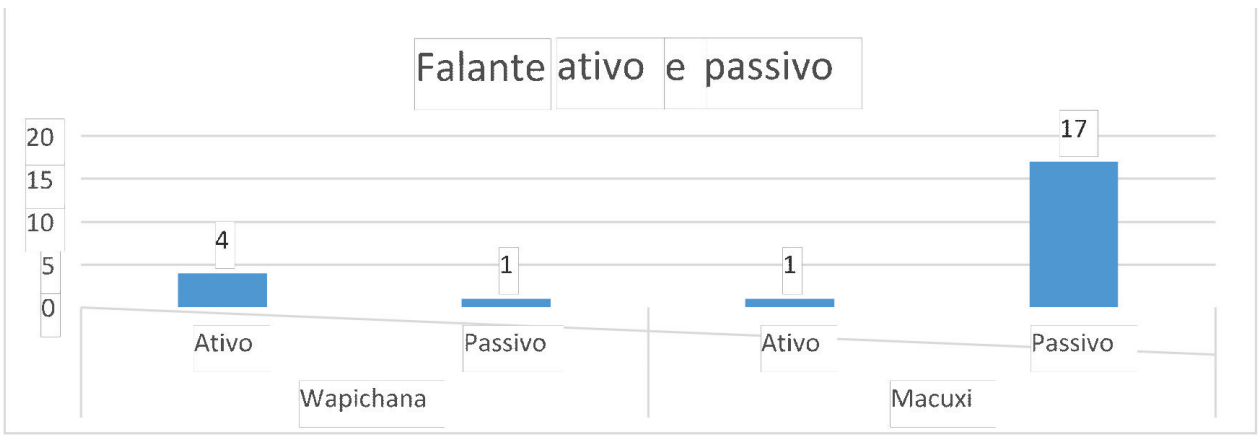

Fonte: As próprias autoras (2018).

Quando a pesquisa foi realizada nessa unidade escolar, ao serem questionados sobre sua identificação como indígenas, apesar de seus aspectos físicos a evidenciarem, muitos dos alunos sentiram vergonha, uns até saíram da sala e não aceitaram responder aos questionários. Essa observação ratifica o afirmado na entrevista de Marliete: "a juventude precisa trabalhar para uma construção da própria identidade, precisa de uma reconstrução da própria identidade [...] [e assim] passará a dar valor à cultura do próprio povo e também a sua língua".

A Secretaria Municipal de Educação de Bonfim reconheceu a diversidade linguística existente nas escolas municipais, porém não possuía informações estatísticas sobre quais eram as línguas indígenas faladas e nem mesmo sobre as ações desenvolvidas para reconhecer as línguas indígenas dentro do espaço escolar.

Segundo Elinalva Froz, atual Chefe de Divisão de Ensino: "as línguas indígenas, sim, devem ser ensinadas dentro das escolas do município, também temos alunos indígenas. A maioria não tem essa comunicação que os pais têm. Há relatos de que os pais falam, mas os filhos não falam". Ela concorda que promover a interação linguística seria uma das maneiras de trabalhar as culturas indígenas dentro do espaço escolar, uma vez que são muitas culturas presentes nos processos educacionais em região de fronteira. Segundo Elinalva:

Já temos a maior dificuldade na língua inglesa, imagina voltada à questão da língua indígena na sede nas escolas municipais, no momento seria oferecida apenas nas escolas indígenas e nas comunidades, e futuramente nas escolas da sede, visto que na sede há um grande quantitativo de alunos indígenas. 
Segundo as observações durante o processo da pesquisa, ao serem questionados sobre as línguas indígenas, os alunos em algumas das turmas, na empolgação, levantaram as mãos, porém, vendo que alguns coleguinhas caçoavam, aqueles que haviam levantado a mão recuavam, negando, dizendo que não, que apenas os pais falavam em casa. Percebe-se que isso acontece por causa do preconceito que eles têm com eles mesmos, sentem vergonha de falar, por não haver incentivo em casa e muito menos na escola. Mas alguns se autodeclararam indígenas mesmo com timidez e afirmaram que falavam a língua em casa com os pais.

Disse Rita Arlene (Wapichana, estudante da EMOFC): "Vai ser muito legal escrever a língua que eu e a minha mãe fala em casa, aprender na sala de aula, vai ser muito bom". Apesar do esforço de seus pais, Rita diz que na escola tem vergonha de falar e que muitos de seus colegas de classe também têm vergonha de falar, com medo de que seus colegas "tirem brincadeirinhas sem graça". Seu Haroldo Aluísio, pai de Rita, declarou, com firmeza em seu olhar: "minha língua original ninguém vai esquecer". Ele tem esperança de que, no futuro, a Língua Wapichana seja ensinada em sala de aula na escola de seus filhos.

Outra jovem estudante, Maria Viana, afirmou não ter vergonha de ser chamada de indígena. Ela fala e entende Wapichana, é neta de Elcir Joaquim, que disse fazer questão de manter os costumes de seu povo e conhecimentos em relação ao bem viver das gerações indígenas. Elcir contou que toma como base os valores de sua cultura na hora de combater os conflitos presentes na realidade, como as drogas, por exemplo. Elcir destacou: "digo aos meus netos para não se perder neste mundo das drogas, temos que nos apegar a nossa raiz Wapichana". Ela dá muito valor à sua cultura: "de geração em geração vou ensinar minha língua e costumes do povo Wapichana" (Entrevista, 2017).

Também há estudantes como Alcione Peres, aluna Wapichana do 9o ano, que declarou não falar, mas entender a língua indígena. Ela disse que os pais falam Wapichana entre si em casa, algumas das vezes falam com os filhos, mas com eles falam mais Inglês e Português. E em relação à cooficialização, ela acha muito importante reconhecer essa diversidade cultural que há na fronteira. Destacou: "É importante valorizar e preservar a língua e a cultura". Seus pais, Jaime Peres e Bernadeth Peres, muitas vezes se sentem tristes por não falarem com seus filhos na Língua Wapichana. Jaime disse que, quando os filhos eram crianças, não falavam 
com eles na Língua Wapichana. "Hoje eles não falam, só entendem". Disse sentir muito por isso. "Creio que a língua e a cultura têm um significado especial para nos revelar e nunca esquecer as nossas origens". Ele acredita que as línguas devem ser ensinadas nas escolas. "Muito mais que apreender a língua, o importante é valorizar o que temos o e que somos: Wapichana" (Entrevistas, 2017).

Com os familiares dos discentes moradores do Bairro São Francisco, as entrevistas foram realizadas de forma semiaberta. Trabalhamos com 13 famílias dos discentes da Escola Municipal Oscar Fernandes Costa, falantes das Línguas Macuxi e Wapichana. A mais idosa dos entrevistados foi dona Madalena, com 93 anos. Constatamos, em algumas visitas realizadas a essa família, que todos são falantes da Língua Wapichana e os pais vivem falando diariamente com seus filhos nas três línguas: Wapichana, Inglês e Português. É interessante o apreço que eles têm pela cultura e língua, demostrado quando se expressam com mais empolgação e com sorriso ao falar Wapichana.

Entre os entrevistados, 10 são indígenas do povo Wapichana, a maioria deles é analfabeta. Todos possuem os documentos de identidade, CPF, Carteira de Trabalho, Rani e têm seus filhos e netos matriculados na Escola Municipal Oscar Fernandes Costa. Esses homens e mulheres são oriundos da República Cooperativa da Guiana, tendo chegado a Bonfim no início dos anos 1970, em sua grande maioria oriundos da Região 9: Maruranau, Awaruana e Região do Rupununi. Sua migração foi em decorrência da busca de melhores condições de vida para os filhos e para conseguir trabalho. Muitos conseguiram adaptar-se ao novo lugar com ajuda dos parentes, principalmente dos que já viviam nas comunidades Manoá e Pium, , na Região Serra da Lua. A maioria disse que a dificuldade que tiveram no início foi em relação à Língua Portuguesa, pois falavam Inglês, Wapichana ou só a Língua Wapichana.

Nenhum deles sabia da existência da Lei Municipal 211/2014, que cooficializou as línguas Macuxi e Wapichana no município de Bonfim. Vendo isso, tivemos de falar da lei de cooficialização, defendendo que foi uma grande conquista para as comunidades falantes aumentarem o reconhecimento e prestígio dessas línguas.

Como soluções para a valorização das línguas e culturas, eles sugeriram iniciativas de um Ciclo de Culturas e Línguas Indígenas no Bairro São Francisco, que foi organizado com o grupo de falantes das Línguas Macuxi e Wapichana para 
diálogo, contação de histórias do povo e Parixara (música e dança).

\section{COMENTÁRIOS FINAIS}

Foi confirmada a presença de uma rica diversidade de línguas e culturas em Bonfim, especificamente nas escolas municipais da sede. A pesquisa foi considerada um espaço de promoção de novas atitudes para que o município de Bonfim assuma sua realidade multilíngue, defendendo que todas as línguas ali faladas deverão ser ensinadas de alguma forma e, neste caso, que sejam mantidas as línguas indígenas, em especial o Macuxi e o Wapichana, para que estas ocupem a posição de línguas de comunicação dentro dos espaços escolares e por onde haja falantes dessas línguas.

Dessa forma, o ensino multilíngue possibilitará aos alunos uma maior participação nos diferentes grupos sociais, com capacidade de inserção e desenvolvimento social e cultural. As línguas indígenas também deverão ter espaço de ensino garantido dentro das escolas, reconhecendo sua existência e a necessidade de continuidade do uso destas línguas que constituem historicamente e, desde 2014, legalmente o quadro linguístico de Bonfim.

Como resultado da aplicação dos métodos, foi possível construir um panorama do universo das duas escolas municipais da sede de Bonfim, de forma que se especificassem e aprofundassem as informações sobre o uso e o prestígio das línguas Macuxi e Wapichana, demostrando nos gráficos os resultados da pesquisa.

$\mathrm{Na}$ infindável luta pela garantia de direitos, as lideranças indígenas são e continuarão sendo as principais responsáveis por suas conquistas. A lei de regulamentação prevê que as instituições públicas deverão ter um número de funcionários falantes das línguas cooficiais compatível com a demanda. Para isso, em 2018, na iniciação científica, começamos um diagnóstico sociolinguístico na sede do município de Bonfim que contribuirá para a implementação da Lei 211/2014.

Nessa direção, é necessário continuar a contabilizar o número de falantes das línguas Macuxi e Wapichana em todo o município, inclusive nas comunidades indígenas, o que uma outra liderança Wapichana, pelo Programa de Valorização das Línguas e Culturas Macuxi e Wapichana (Iniciação Científica - UFRR), já começou a fazer também. Assim, contribuiremos para elaboração de uma política linguística 
consistente no município, uma vez que uma das etapas iniciais da implementação da Lei 211/2014 está sendo realizada através desses diagnósticos.

\section{REFERÊNCIAS}

BHABHA, Homi. O local da cultura. Tradução Myriam Ávila, Eliana Lourenço de Lima Reis e Gláucia Renata Gonçalves. Belo Horizonte: Editora UFMG, 2003.

BONFIM (Município). Lei 211, de 4 de dezembro de 2014. Pesquisa realizada in loco.

BRASIL. Lei n. 9.394/96, de 20 de dezembro de 1996. Estabelece as Diretrizes e Bases da Educação Nacional (LDB). Disponível em: http://www.planalto.gov.br/ccivil_03/leis/ 19394.htm. Acesso em: 25 nov. 2019.

CADETE, Casimiro Manoel. Dicionário Wapichana/Português - Português/Wapichana. São Paulo: Edições Loyola, 1990.

CALVET, Louis Jean. As políticas linguísticas. São Paulo: Parábola: IPOL, 2007.

CALVET, Louis Jean. La guerre des langues et les politiques linguistiques. Paris: Hachette Littératures (Pluriel), 1999.

CARNEIRO, João Paulo Jeannine Andrade. A morada dos Wapixana: Atlas Toponímico da Região Indígena Serra da Lua- RR. 2007. Dissertação (Mestrado em Semiótica e Linguística Geral)- Universidade de São Paulo, São Paulo, 2007.

FARACO, Carlos Alberto. Questões de política de língua no Brasil: problemas e implicações. Educar em Revista, Curitiba, n. 20, p. 13-22, 2002.

FRANCHETTO, Bruna. Línguas em perigo e línguas como patrimônio imaterial: duas ideias em discussão. Revista do Patrimônio Histórico e Artístico Nacional, Rio de Janeiro, n. 32, p. 182-205, 2005.

HAMEL, Rainer Enrique. La política del lenguaje y el conflicto interétnico: problemas de investigación sociolingüística. In: ORLANDI, Eni P. (Org.). Política lingüística na América Latina. Campinas, SP: Pontes, 1988. p. 41-73.

INSTITUTO BRASILEIRO DE GEOGRAFIA E ESTATÍSTICA (IBGE). Os indígenas no Censo Demográfico 2010: primeiras considerações com base no quesito cor ou raça. Rio de Janeiro: IBGE, 2010. 
INSTITUTO DO PATRIMÔNIO HISTÓRICO E ARTÍSTICO NACIONAL (IPHAN). Guia de Pesquisa e Documentação para o INDL: Volume 1 Patrimônio Cultural e Diversidade Linguística. Brasília: IPHAN, 2016a.

INSTITUTO DO PATRIMÔNIO HISTÓRICO E ARTÍSTICO NACIONAL (IPHAN). Guia de Pesquisa e Documentação para o INDL: Volume 2 Formulário e Roteiro de Pesquisa. Brasília: IPHAN, 2016b.

MACHADO, Ananda. Kuadpayzu, Tyzytaba'u na'ik Marynau: aspectos de uma história social da língua Wapichana em Roraima (1932-1995). 2016. Tese (Doutorado em História Social) - Universidade Federal do Rio de Janeiro, Rio de Janeiro, 2016.

MAHER, Terezinha de Jesus Machado. Políticas linguísticas e políticas de identidade: Currículo e Representações de professores indígenas na Amazônia Ocidental Brasileira. Currículo sem Fronteiras, v. 10, n. 1, p. 33-48, jan./jun. 2010.

MORELLO, Rosângela (Org.). Leis e Línguas no Brasil. O processo da cooficialização e suas potencialidades. Florianópolis: IPOL, 2015.

OLIVEIRA, Gilvan Müller de. Políticas linguísticas: uma entrevista com Gilvan Müller de Oliveira. ReVEL, v. 14, n. 26, p. 382-99, mar. 2016.

OLIVEIRA, Alessandro Roberto. Tempos dos netos: abundância e escassez nas redes de discursos ecológicos entre os Wapichana na Fronteira Brasil-Guiana. 2012. Tese (Doutorado em Antropologia Social) - Universidade de Brasília, Brasília, 2012.

PEREIRA, Mariana Cunha. A escola da fronteira: diversidade e cultura na fronteira BrasilGuiana. Inter-Ação: Revista da Faculdade de Educação, Goiânia, v. 32, n. 2, p. 345-61, jul./dez. 2007.

RODRIGUES, Aryon Dall'Igna. Línguas indígenas: 500 anos de descobertas e perdas. Delta, São Paulo, v. 9, n. 1, p. 83-103, 1993.

SANTOS, Alessandra de Souza. Multilinguismo em Bonfim/RR: o ensino de Língua Portuguesa no contexto da diversidade linguística. 2012. Tese (Doutorado em Linguística) - Universidade de Brasília, Brasília, 2012.

TOLLEFSON, James W. Planning language, planning inequality. Londres: Longman, 1991.

VEIGA, JURACILDA (Org.). Questões de Educação Escolar Indígena: da formação do professor ao projeto da escola. Brasília: FUNAI DEDOC, 2001. 


\section{Sobre as autoras:}

Jama Peres Pereira: Graduada em Gestão Territorial Indígena, com ênfase em Patrimônio Indígena. Foi bolsista de iniciação científica (2017 e 2018). Colaboradora como monitora e professora de Língua e Cultura Macuxi e Wapichana no Programa de Valorização das Línguas e Culturas Macuxi e Wapichana (Pró-Reitoria de Assuntos Estudantis e Extensão/UFRR). E-mail: jamapereiras2@hotmail.com, Orcid: http://orcid.org/0000-0003-1674-762X

Ananda Machado: Pós-doutoranda no Programa de Pós-Graduação em Literatura da Universidade Federal Fluminense (UFF). Bolsista PROCAD CAPES. Professora no Programa de Pós-Graduação em Letras e no curso de Gestão Territorial Indígena, no Instituto Insikiran, da Universidade Federal de Roraima (UFRR). Coordenadora do Programa de Valorização das Línguas e Culturas Macuxi e Wapichana (PróReitoria de Assuntos Estudantis e Extensão/UFRR). E-mail: machado.ananda@ gmail.com, Orcid: http://orcid.org/0000-0002-3363-2587

Recebido em 25 de março de 2019

Aprovado para publicação em 29 de julho de 2019 
